\title{
Absence of a market in the Dutch balancing mechanism: European rules versus specific investments
}

\author{
Authors: dr. Eva Niesten and prof. dr. Albert Jolink
}

\begin{abstract}
The European directives for the electricity industry prescribe the creation of a market for balancing electricity supply and demand. In this paper, we demonstrate that a market for balancing has not emerged in the Dutch electricity industry, and that, instead, the balancing transactions are governed by regulated, long-term contracts and a bidding mechanism. We explain the absence of a balancing market by using the framework of transaction cost economics, in which the efficiency of a market decreases with increasing investments in specific assets. The results of a questionnaire among the energy firms that supply balancing power in the Dutch setting show that these firms have invested in specific physical, temporal and dedicated balancing assets. The need for these specific investments to balance supply and demand does not only explain the absence of a market, but also the lack of participation by small firms in the balancing mechanism. We recommend several policies, such as stimulating technological developments for the storage of electricity and demand side management, which reduce these specific investments in balancing assets, and thereby stimulate the creation of a market and the participation of small firms.
\end{abstract}

Keywords: Balancing mechanism; specific investments; electricity market; European rules, transaction cost economics.

JEL Codes: D23; K23; L22; L94; Q48 


\section{Introduction}

Since 2003 the European directives for the electricity industry prescribe the implementation of a market for the balancing of electricity supply and demand. The directives state that "cost-reflective balancing mechanisms are necessary" and that "this should be achieved through the setting up of transparent market-based mechanisms for the supply and purchase of electricity needed in the framework of balancing requirements" (EC 2003: 38; EC 2009: 59). A balanced electricity system is a system in which the amount of electricity that is produced is equal to the amount of electricity that is consumed. The continuous balancing of electricity supply and demand is necessary for the safety of the electric system and the security of supply. In the European electricity industries, the transmission system operators (the operators of the high-voltage electricity network) and the energy firms are responsible for maintaining the balance of supply and demand on the network. To achieve a balance of supply and demand in real time, energy firms supply balancing power to the transmission system operator (TSO), or in other words, they increase or decrease their electricity production at the request of the TSO. The European Commission prescribes the creation of balancing markets for this type of balancing transaction. Energy firms thus need to supply balancing power to the TSO through a market.

In its 2007 Energy Sector Competition Inquiry, the European Commission concludes, however, that the EU wholesale electricity markets are not yet functioning properly (EC 2007). With respect to balancing, the Inquiry mentions that the balancing markets are highly concentrated and create barriers to entry for small energy firms. Others have indicated that the balancing system is not a real market (Van der Veen and De Vries 2009), and that the design of the balancing mechanism deviates from a market-based design (Vandezande et al. 2010). 
Several barriers to the creation of real balancing markets have been identified in the literature, such as the inclusion of penalties in the imbalance price, contracting of large amounts of reserve capacity by the TSO, large payments for reserve capacity, and a limited unbundling of the TSO (EC 2007; Glachant and Saguan 2007; Vandezande et al. 2010).

In this paper, we study the Dutch balancing mechanism in detail, and demonstrate that a market for balancing has also not emerged in the Dutch electricity industry, and that the smaller players in this industry do not participate in the balancing mechanism. We illustrate that the Dutch balancing transactions are governed instead by long-term, regulated contracts. On the basis of a questionnaire sent to the ten energy firms that supply balancing power, we provide reasons for the absence of a market that differ from and complement those that are highlighted in the recent literature. Our explanation is based on insights from transaction cost economics, in which large transaction costs and specific investments feature as reasons for the absence of a market (Williamson 1996). This alternative perspective is able to provide complementary suggestions for policy on how to create a market for balancing. These policy recommendations are not restricted to the Dutch industry, but are valuable for other Member States, and for electricity industries that are confronted with the need to transform their balancing mechanism.

This paper is structured as follows. Section 2 presents the details of the Dutch regulated, long-term contracts for balancing and the absence of a market, and it demonstrates that small firms do not participate in the balancing mechanism. Section 3 discusses some of the relevant literature on balancing. Section 4 presents the results of the questionnaire. In particular, it demonstrates that the energy firms have invested in specific balancing assets, which provide a reason, 
following the transaction cost logic, for the absence of a market. Section 5

presents suggestions for policymakers on how to reduce the specific investments, thereby stimulating the emergence of a market and the participation of smaller players. Section 6 concludes.

\section{Regulated long-term contracts for Dutch balancing}

In this section, we will first discuss the absence of smaller players in the Dutch balancing mechanism, and the attempts and failure to create a balancing market in the Dutch electricity industry. In the absence of a market for balancing, we answer the following question: Which structure governs the Dutch balancing transaction? We will characterize the current governance structure of the Dutch balancing transaction using a transaction cost economics framework. Williamson (1996) identified three attributes of the structures that govern transactions (incentive intensity of the actors, administrative control mechanisms, and type of contracts), leading either to a characterization of a governance structure as a market, a hybrid, or a vertically integrated firm.

\subsection{Program responsibility and balancing in the Dutch industry}

Every economic actor in the Dutch electricity industry, whether it is an electricity producer or a consumer, has the legal responsibility to match the electricity that it consumes to the electricity that it puts on the network. This is referred to as program responsibility. Firms that are registered by the Dutch TSO (TenneT) as program responsible parties (PRPs) may take over the program responsibility of other actors in the industry. The electricity producers, for instance, take over the 
program responsibility of the households and small businesses, and thereby try to match the electricity consumption of these actors to electricity production. TenneT publishes a list of all the PRPs in the Dutch electricity industry. Synthesizing the diversity of the PRPs on this list of TenneT, we distinguish three types of actors. First, the producers, a combination of Dutch incumbents, incumbents merging with European partners, and foreign producers who have acquired Dutch production capacity. In terms of market share, the producers by far outweigh the other two types of actors. Second, the traders, a combination of producers with electricity production capacity abroad but only trading capacity in the Netherlands, and commodity traders of Dutch or non-Dutch origin. Finally, the aggregators, who bundle the program responsibility of smaller firms and who's aim it is to reduce costs by balancing the collective supply and demand of electricity. The greater the number and diversity of firms that are aggregated, the greater the likelihood that the variations in their separate supply and demand of electricity will cancel one another out, and will reduce balancing costs. At the end of 2010, the list of TenneT included 27 PRPs, of which 10 are characterized as producer, 13 as trader, and 4 as aggregator. While PRPs are responsible for balancing their own electricity supply and demand, TenneT is responsible for balancing electricity supply and demand in real time for the entire Dutch electricity network in order to ensure the safety of the electric system and the security of supply. Because the PRPs are often not able to achieve their own balance in real time, TenneT resolves these individual imbalances for the entire network. To maintain the real-time and system-wide balance, several PRPs supply so-called balancing power to TenneT. When an energy firm wishes to supply balancing power to TenneT, it needs to be registered as a PRP. Of the three types of PRPs in the Dutch electricity industry, only the producers are involved in the 
supply of balancing power to TenneT. In this paper, we therefore make a distinction between the 27 PRPs, which are responsible for maintaining their own balance of electricity supply and demand, and the 10 producers, which are PRPs that supply balancing power to TenneT to contribute to the balance of electricity supply and demand in real time for the entire Dutch electricity network. For ease of distinction, we refer to the PRPs that supply balancing power to TenneT as balancing responsible parties (BRPs). The 10 producers that supply balancing power to TenneT (i.e. the BRPs) are large energy firms with revenues ranging from 2.1 billion euro to 92.9 billion euro in 2010 . We must therefore conclude that the smaller energy firms (for instance, the new energy firms that have entered the industry during liberalization) do not participate in the Dutch balancing mechanism.

\subsection{The unsuccessful single-buyer market}

Since the beginning of the 1990s, the European Commission and national governments in the European Union have focused their energy policies almost exclusively on the introduction of competition into the European electricity industries (Eising 2002: 92). To attain the goal of creating one European competitive electricity market, the European Parliament and Council issued three electricity directives, in 1996, 2003, and 2009, on common rules for electricity production, transmission, distribution and retail. These directives prescribe the vertical unbundling of transmission and distribution from the integrated electricity firms, to enable the introduction of competition into the production and retail of electricity. The reason for developing these European electricity directives can be found in the EU internal market program, with its goal of creating a common 
market aimed at establishing the free movement of goods, services, labour and capital. The 2003 and 2009 directives also stipulate the introduction of competition into the balancing of electricity supply and demand. These directives state that "non-discriminatory and cost-reflective balancing should be achieved through the setting up of a transparent market-based mechanism for the supply and purchase of electricity needed in the framework of balancing requirements" (EC 2003; 2009). The European directives have been implemented into Dutch electricity laws and regulations.

In 2000, the Dutch TSO set up a single-buyer market to coordinate the transaction for the supply of balancing power by the BRPs to the TSO. Balancing power can be either regulating power or reserve power. Regulating power must be made available to the TSO within 30 seconds, and reserve power is used when the TSO decides that the regulating power is used for too long and too extensively. On the single-buyer market, the BRPs bid for the supply of regulating and reserve power to TenneT. At first, the Dutch regulator for the electricity industry (DTe / Energiekamer) and TenneT aimed to rely solely on this single-buyer market, "but by mid 2000 , there was an unsuccessful tender for regulating and reserve power" (Beune and Nobel 2001: 48). At that time, the regulator concluded that a market for balancing power was not likely to emerge in the Dutch electricity industry, because the electricity producers were not willing to contract with the TSO for the necessary capacity to supply regulating and reserve power (DTe 2000). The regulator therefore obliged the electricity producers, with a capacity larger than 60 MW, to engage in long-term contracts with TenneT for the supply of reserve power. The regulator stipulated this obligation in the Grid Code, which is regulation that prescribes how the network operators and the users of the electricity network (e.g. producers, retailers, consumers) have to behave with 
respect to the operation of the network and the transportation of electricity. On the basis of these long-term contracts, the large electricity producers bid for the supply of reserve power to TenneT. Other BRPs with a capacity of less than 60 MW can bid for the supply of reserve power to TenneT on a voluntary basis. As the regulator's main objective was to arrange for a sufficiently large supply of reserve power to TenneT, the regulator only obliged the larger electricity producers with a capacity of more than $60 \mathrm{MW}$ to contract with TenneT. This obligation had to ensure the reliability of the Dutch electricity supply (DTe 2000: 3). In 2000, the BRPs with a capacity larger than $60 \mathrm{MW}$ consisted of four large electricity producers (EPON, EPZ, UNA, EZH) that together had a share of close to 70 per cent of the total production capacity in the Dutch industry (IEA 2000: 83). In addition to the compulsory contracts for the supply of reserve power, TenneT also contracts with BRPs for the supply of $250 \mathrm{MW}$ of regulating power. The BRPs bid for the supply of regulating power on the single-buyer market up to their contracted amount. Other BRPs, which do not have such a contract with TenneT, can bid for the supply of regulating power on a voluntary basis. The Dutch balancing transaction (i.e. the supply of regulating and reserve power by BRPs to the TSO in order to balance supply and demand of electricity for the entire electricity network in real time) is thus governed by regulated, long-term contracts and a bidding mechanism, and cannot rely solely on the single-buyer market. 


\subsection{Hybrid governance of Dutch balancing transaction}

Using a transaction cost economics framework, we will characterize the governance structure of the Dutch balancing transaction in detail. We analyse the supply of regulating power and the supply of reserve power as part of one balancing transaction. The following subsections will show that the supply of these two types of power are highly interconnected, but differences between regulating and reserve power will be explicitly indicated. Williamson (1996) has identified three attributes of governance structures: incentive intensity, administrative control and contract law. Table 1 summarizes the differences between a market and a hybrid form of governance on the basis of these attributes. We will conclude that the governance structure for the Dutch balancing transaction is not a market, but a hybrid form that is heavily influenced by regulation.

First, incentive intensity has been defined as the degree to which changes in efforts expended by an economic actor have an immediate effect on his compensation or stream of revenues (Williamson 1996: 99). Markets are characterized by high-powered incentives, because contracting parties to a market receive immediate, individual streams of revenue for their efforts (Williamson 1996: 103). An intermediate incentive intensity characterizes the hybrid structure, and indicates that a part of the income to be earned cannot be influenced by the economic actor.

Second, administrative control refers to the various mechanisms that support the functioning of governance structures. Markets are characterized by very few administrative control mechanisms, but they may consist of rating services that compare standard products of various suppliers. The administrative control mechanisms of hybrids include monitoring, information disclosure and 
information verification mechanisms, and specialized dispute settlement procedures (Williamson 2000: 606).

Third, at least two types of contract law can be distinguished: classical contract law and neoclassical contract law, which support the market and the hybrid, respectively (Williamson 1991). Classical contract law refers to short-term contracts that describe in great detail the conditions under which exchange takes place. Contracts are ended when disputes arise, and courts are reserved as a forum for ultimate appeal (Williamson 1994: 325). Neoclassical contract law supports contracts with a greater degree of flexibility and a longer duration. Joskow (1987: 168) defined contracts with a duration of one year or longer as long term. Thirdparty involvement in these contracts is common to observe performance or to settle disputes through arbitration.

Table 1. Governance attributes of markets and hybrids

\begin{tabular}{|l|l|l|l|}
\hline & $\begin{array}{l}\text { Incentive } \\
\text { Intensity }\end{array}$ & Administrative Control & Contract Law \\
\hline Markets & $\begin{array}{l}\text { High } \\
\text { incentive } \\
\text { intensity }\end{array}$ & $\begin{array}{l}\text { Very few control } \\
\text { mechanisms (e.g. rating } \\
\text { services) }\end{array}$ & $\begin{array}{l}\text { Classical contract law: } \\
\text { short-term, inflexible } \\
\text { contracts; court as forum } \\
\text { for ultimate appeal }\end{array}$ \\
\hline Hybrids & $\begin{array}{l}\text { Intermediate } \\
\text { incentive } \\
\text { intensity }\end{array}$ & $\begin{array}{l}\text { Monitoring; information } \\
\text { disclosure and verification } \\
\text { mechanisms; dispute } \\
\text { settlement procedures }\end{array}$ & $\begin{array}{l}\text { Neoclassical contract law: } \\
\text { long-term, flexible } \\
\text { contracts; third party } \\
\text { involvement; dispute } \\
\text { resolution via arbitration }\end{array}$ \\
\hline
\end{tabular}

In the following three subsections, we will characterize the governance structure of the Dutch balancing transaction along the three attributes. The data that we have used for the characterization are publicly available documents, published by the regulator (e.g. Grid Code and System Code) and by the TSO. The Grid Code and System Code specify the rules that firms have to abide by when sending bids 
to TenneT. In other documents, TenneT provides more specific instructions for the bidding by energy firms, including execution rules of the Grid and System Code (TenneT 2007; 2011; 2012), and a manual on the supply of balancing power (TenneT 2003; 2005).

\subsubsection{Intermediate incentive intensity}

The governance of the Dutch balancing transaction is structured and regulated in such a way that the incentive intensity of the BRPs remains at an intermediate level, and has not increased to a level at which efforts by these BRPs can immediately increase their stream of revenue. The following discussion on the bidding mechanism will illustrate why this is the case.

When bidding for the supply of regulating and reserve power, the BRPs stipulate a price for which they are willing to supply the electricity in the different program time units (1 PTU = fifteen minutes $)$ of the next day. They give two different prices: one to increase their input into the network, and one to decrease their input into the network. TenneT places these bids for regulating and reserve power on one bid ladder, and in increasing order of price for each PTU. Tennet calls first on the amounts offered with the lowest price, and then proceeds to the higher prices. The BRPs that supply balancing power in a PTU are paid the price of the highest bid that TenneT uses in that particular PTU, which is referred to as the regulating price (RP) (DTe and TenneT 2004: 9). For operational purposes, TenneT separates the bid ladder into two parts: one ladder for regulating power and one ladder for reserve power. TenneT makes estimates of how much regulating power it needs in every PTU. The difference between the regulating power that is bid by BRPs and the estimates of TenneT, is added to the ladder of reserve power (DTe 
and Tennet 2004: 8; TenneT 2011: 3). Reserve power is only used when large or unexpected imbalances occur, when the available regulating power falls below $100 \mathrm{MW}$ and the expectation is that this will last for several PTUs (Tennet 2011: 4-5). When reserve power is needed, the surplus of regulating power that was added to the ladder of reserve power is made available as regulating power (DTe and TenneT 2004: 8). TenneT publishes the amounts of regulating and reserve power that have been used in each PTU on its website. For instance, in 2012, in only $0,0016 \%$ of all the PTUs reserve power was used to decrease the amount of electricity on the network, and in $0,004 \%$ of all the PTUs reserve power was used to increase the amount of electricity on the network. The great majority of realtime balancing is thus performed by the supply of regulating power. The regulating and reserve power that is offered by BRPs must meet certain requirements, the most important ones are a bid size between 5 and $200 \mathrm{MW}$, bid prices between -100.000 and 100.000 euro/MWh, and, for regulating power, a regulating speed that is higher than $7 \%$ / minute and a response time for regulating power no more than 30 seconds (Van der Veen and De Vries 2009: 2789; TenneT 2011). The response time for reserve power can be 1 or 2 PTUs (TenneT 2012). The BRPs thus receive the regulating price from TenneT for their contribution to the real-time balance on the electricity network, and TenneT transfers these costs for balancing power to the PRPs that have caused the imbalance. These PRPs do not only include the 10 BRPs, but also the 17 other PRPs that do not supply balancing power (see subsection 2.1). PRPs must send projections of their consumption and production to TenneT on the day before real time. These dayahead projections are called energy programs. If the real time consumption and production of a PRP differ from its energy programs, it must pay the costs for this imbalance to TenneT in the form of the imbalance price (IP). Table 2 illustrates 
that the imbalance price is based on the regulating price, and that it depends on both the system imbalance, and thus on whether there was a system shortage, a system surplus or both (bidirectional dispatching), and on whether the PRP increased or decreased its input into the network relative to its energy program.

Table 2. Schedule of imbalance prices that PRPs pay to (receive from) TenneT

\begin{tabular}{|l|l|l|l|}
\hline \multirow{2}{*}{} & \multicolumn{2}{|c|}{ Unidirectional dispatching: } & Bidirectional dispatching: \\
\cline { 2 - 4 } & System shortage & System surplus & \\
\hline $\begin{array}{l}\text { PRP* decreases } \\
\text { input into network: }\end{array}$ & $\begin{array}{l}\text { 1: PRP pays IP* to TenneT } \\
\text { that is based on RP* for } \\
\text { increasing input }\end{array}$ & $\begin{array}{l}\text { 3: PRP pays to TenneT IP } \\
\text { that is based on RP for } \\
\text { decreasing input }\end{array}$ & $\begin{array}{l}\text { 5: PRP pays to TenneT RP } \\
\text { for increasing input }\end{array}$ \\
\hline $\begin{array}{l}\text { PRP increases input } \\
\text { into network: }\end{array}$ & $\begin{array}{l}\text { 2: PRP receives IP from } \\
\text { TenneT that is based on } \\
\text { RP for increasing input }\end{array}$ & $\begin{array}{l}\text { 4: PRP receives from } \\
\text { TenneT IP that is based on } \\
\text { RP for decreasing input }\end{array}$ & $\begin{array}{l}\text { 6: PRP receives from } \\
\text { TenneT RP for decreasing } \\
\text { input }\end{array}$ \\
\hline
\end{tabular}

* PRP: program responsible party; IP: Imbalance price; RP: Regulating price

In case of a system shortage, when TenneT has to increase the input into the network and the PRP decreases its input, the PRP has to pay to TenneT the imbalance price that is based on the regulating price for increasing the input (box 1 in table 2). In case of a system shortage, when TenneT has to increase the input into the network and the PRP increases its input, the PRP has to receive from TenneT the imbalance price that is based on the regulating price for increasing the input (box 2). In case of a system surplus, when TenneT has to decrease the input into the network and the PRP decreases its input, the PRP has to pay to TenneT the (at times negative) imbalance price that is based on the regulating price for decreasing the input (box 3). In case of a system surplus, when TenneT has to decrease the input into the network and the PRP increases its input, the PRP has to receive from TenneT the (at times negative) imbalance price that is based on the regulating price for decreasing the input (box 4). When in one PTU, TenneT has to both increase and decrease its input into the network (i.e. bidirectional dispatching), the imbalance prices that the PRPs pay (or receive) cannot depend 
on the system imbalance. In this case, when PRPs decrease their input relative to their energy programs they pay to TenneT the regulating price for increasing input (box 5). When the BRPs increase their input relative to their energy programs, they receive from TenneT the regulating price for decreasing input (box 6) (TenneT 2005: 10).

Table 2 illustrates that the imbalance prices are difficult to predict for PRPs, because the prices depend on whether TenneT dispatched bidirectional or whether TenneT dispatched in one direction only. The governance structure for the Dutch balancing transaction has been intentionally designed in this way (Glachant and Saguan 2007). In this set-up, PRPs should not be able to predict the imbalance price that they have to pay or receive in any of the PTUs, and hence they should not be stimulated to profit from creating an imbalance. An imbalance should be a priori unintentional, and a posteriori minimal (Beune and Nobel 2001: 49). BRPs thus receive the regulating price for supplying balancing power to TenneT, and they must pay the imbalance price to TenneT when they deviate from their own energy programs. The incentive intensity of the BRPs is restricted and is not as high as in a market, because the imbalance prices are linked to the regulating prices (see table 2), and thus to the prices that the BRPs bid on the balancing mechanism. The BRPs will not set their bid prices too high in order to avoid high regulating prices and thus high imbalance prices. If by some unexpected event, the BRP deviates from its own energy program and creates an imbalance, it would have to pay this high imbalance price. Fundamental factors that can cause deviations from forecasts include unplanned power outages, errors in weather forecasting, load forecast errors, and leaps in electricity supply (Paulus and Borggrefe 2011: 434). Due to this link between bid prices, regulating prices and imbalance prices, and the unpredictable deviations from energy programs, the 
incentive intensity of BRPs is characterized as being of an intermediate degree. The revenues of BRPs thus depend on unpredictable events outside of their control, and are therefore not only influenced by their own efforts at increasing revenues.

\subsubsection{Administrative control of a hybrid}

The administrative control mechanisms that govern the balancing transaction include mechanisms for monitoring the BRPs and various information disclosure mechanisms, both of which belong to the administrative apparatus of a hybrid structure (Williamson 2000). BRPs are monitored in this balancing mechanism, because the TSO keeps track of the amount of electricity that the BRPs put on and take out of the network. In particular, the TSO checks whether the BRPs have increased or decreased their input into the network as specified in their bids that are called upon by the TSO. If the BRPs deviate from what was specified in their bids, this is registered as an imbalance for the BRPs, and they have to pay the imbalance price. With respect to the information disclosure mechanisms, article 2.2.7 of the System Code states that TenneT should have access to up to date information of the electricity producers with a connected capacity of more than 60 MW (i.e. the producers that are obliged to supply reserve power). After a shortage of electricity supply in the summer of 2003, the System Code was adjusted to include several other information disclosure mechanisms with respect to the availability of production capacity for maintaining the balance of supply and demand (article 2.4 of the System Code). For instance, every electricity producer with a capacity of more than $5 \mathrm{MW}$ has to inform TenneT every three months of the capacity of its electricity production plants. When there is a change in the available production capacity, the production firms have to send this information 
to TenneT within 24 hours. Electricity producers with a capacity of more than 5 MW also have to send information to TenneT on their available capacity that can be used for the supply of balancing power on a daily basis.

\subsubsection{Neoclassical contract law}

The neoclassical contract law of the hybrid structure supports contracts that are flexible, have a duration of one year or longer, and often involve a third party to resolve disputes. The Dutch contracts for the supply of regulating and reserve power between TenneT and the BRPs are flexible, as they do allow for changes to their contents: the System Code specifies among others the procedures for determining the regulating prices, and these procedures can be changed by altering the System Code. The contracts for the supply of regulating and reserve power between TenneT and the BRPs change when the System Code is altered. These contracts for the supply of regulating and reserve power are long-term contracts. The electricity producers with a capacity of more than $60 \mathrm{MW}$ are obliged to supply reserve power to TenneT. They will have this obligation as long as they are connected to the network, and therefore they have a long-term relation with TenneT for the supply of reserve power. The contracts for the supply of regulating power have a duration of one year and TenneT invites tenders for these contracts on an annual basis. The Dutch competition authority (ACM), as a third party, settles the disputes between TenneT and the BRPs with respect to both the supply of regulating and reserve power (Niesten and Jolink 2012ab).

We may conclude that the transactions for the supply of balancing power to TenneT are governed by a hybrid structure, as the structure is characterized by an intermediate degree of incentive intensity, a monitoring of BRPs, information 
disclosure mechanisms, and by long-term, flexible contracts and third-party dispute resolution.

\section{Literature on the absence of balancing markets}

In the literature on the balancing of electricity supply and demand, it has been noted that a market for balancing in the EU does not exist. For instance, Van der Veen and De Vries (2009: 2788) claim that the balancing system is not a real market, and that the term balancing mechanism is therefore more appropriate.

Others, who wish to retain the term 'balancing market', indicate that the European balancing markets are not functioning properly, that they are highly concentrated and create barriers to entry for small energy companies (EC 2007). Vandezande et al. (2010: 3151) point out that "this concentration simply does not allow some balancing markets to function properly on a national scale, and that this explains why many balancing 'markets' are currently more regulated than market-based”. In addition to these studies on the absence of a balancing market, other studies have addressed the lack of participation by small energy firms in the balancing mechanism. Hortaçsu and Puller (2008), for instance, examine the differences in the bidding behaviour by large and small firms in the electricity balancing mechanism of Texas. While firms with large market shares perform close to the theoretical benchmark of static profit maximization, small firms contribute instead to the productive inefficiency of the balancing mechanism. Small firms submit bid functions that are excessively steep, in order to avoid having to supply balancing power. Sioshansi and Oren (2007) also find that small power producers, municipalities, cooperatives and co-generators offer electricity on the Texas balancing mechanism with large markups and markdowns that are far in excess of the optimal supply functions. These optimal supply functions are based on the 
assumption of profit maximization, and take into account the quantity supplied by firms at different prices, their generating costs and the market demand for balancing energy. Sioshansi and Oren (2007: 32) explain the suboptimal behaviour of small power producers by the general reluctance of these actors to participate in the balancing mechanism.

Several studies have identified a few barriers to the creation of balancing markets in the EU that also complicate the participation of small actors. These barriers result from the institutional frameworks surrounding the balancing mechanism and the governance costs associated with balancing (EC 2007; Glachant and Saguan 2007; Newbery 2004; Vandezande 2010).

\subsection{Institutional barriers to a balancing market}

Glachant and Saguan (2007) highlight differences between the institutional frameworks for balancing in the European electricity industries. Some of these institutional frameworks in the European industries include a penalty in their imbalance price, whereas others do not. Glachant and Saguan (2007: 29) demonstrate that the use of penalties increases the volatility of the imbalance price, creates distortions in the forward price, and decreases the welfare of small, disintegrated retailers. Vandezande et al. (2010) have also argued that including penalties in the imbalance settlement is a barrier to a well-functioning balancing market. In addition, they argue that it is preferable to avoid capacity payments, and thus to avoid remunerating firms for keeping capacity available for the supply of balancing power. They also argue that a cap should be imposed on the amount of capacity that is reserved to supply balancing power (Vandezande et al. 2010: 3151). A large reservation of capacity for balancing services could create barriers 
to entry for smaller actors. A similar argument has been made by the Inquiry of the European Commission: "there is a risk that all network users are charged an excessive tariff for using the network, when TSOs pay excessive prices for balancing capacity (MW) to generators" (EC 2007: 296). A related risk, expressed in the Inquiry, concerns the TSOs that are still (partially) integrated with electricity generators. "In some Member States the structural relation between TSOs and their affiliated generation provides an incentive for the TSO to buy excessive reserve capacity and/or to pay high prices, thereby favouring their affiliated generation arm" (EC 2007: 10).

With respect to the Dutch electricity industry, we have seen that a balancing market is absent and that small firms do not participate in the balancing mechanism. Most of the institutional barriers to a balancing market that are identified in the literature are, however, not present in the Dutch industry. For instance, penalties in the Dutch imbalance price have been removed in 2003. In addition, the EC Inquiry provides figures on the purchase of reserves by the TSOs in the EU Member States for 2004 (EC 2007: 307-8). Comparing the Netherlands to the other Member States, we find that the Dutch TSO purchases the second lowest amount of reserves (around 3 per cent of peak load). Only the TSO in Finland purchases lower amounts ( 2 per cent of peak load). TSOs in Greece and Denmark, for instance, purchase close to 14 per cent of peak load in reserves. The envisaged detrimental effects of a partially integrated TSO on the functioning of the balancing market also do not apply to the Dutch industry. The Dutch TSO, TenneT, has been fully unbundled for over a decade. The electricity law of 1998 appoints TenneT as the independent transmission system operator. 


\subsection{Governance costs of balancing}

Other barriers to the establishment of a balancing market can be identified by taking a transaction cost economics approach to the study of the balancing mechanism. Large transaction costs or governance costs may provide reasons for the absence of a market. While several empirical studies on the electricity industry have adopted a transaction cost framework (Joskow 1987, 1996; Friedrichsen 2012), only a few studies have addressed the governance of the balancing mechanism (Newbery 2004; Baudisch 2007). Newbery (2004) pointed to the substantial increase in governance costs in the UK electricity industry as a result of the replacement of the centrally dispatched Pool by the New Electricity Trading Arrangements (NETA). The UK regulatory agency for the electricity industry (Ofgem) estimated the costs of implementing and operating the new trading arrangements to be between 136 to 146 million pound for a five-year period, followed by additional operating costs of 30 million pound per year (Newbery 2004: 19). Newbery argued that these continuing, annual costs almost certainly underestimate the extra costs of maintaining 24/7 trading floors for balancing (Newbery 2004: 19). Baudisch (2007) classified these costs as haggling or frictional costs. Haggling between unbundled electricity producers and retailers of electricity increase as a result of the implementation of NETA, which limited a proper functioning of the market (Baudisch 2007: 19).

\section{Specific investments in balancing by large firms}

Although a few studies have focused on the governance costs of balancing, the impact of specific balancing assets on the creation of balancing markets has been underemphasized in the literature. In this paper, we take a transaction cost 
economics perspective, and study the investments in specific balancing assets in the Dutch electricity industry, and argue that these investments provide a reason for the absence of a market and the lack of participation by small energy firms. We will first define asset-specificity, then present the details of the questionnaire, and finally discuss the results on the degree of specific investments in balancing that are made by the BRPs.

\subsection{Asset-specificity in transaction cost economics}

The specificity of assets refers to "the degree to which an asset can be redeployed to alternative uses and by alternative users without sacrifice of productive value" (Williamson 1996: 59) and ranges from generic, non-specialized assets to intermediate and to highly idiosyncratic assets. Generic, non-specialized assets can be easily transferred to other transactions and alternative uses without great costs. At the other extreme, investments into idiosyncratic assets are made specifically to enable a particular transaction. The core argument of transaction cost economics is that the efficiency of different governance structures depends on the degree of asset-specificity of the transactions (Williamson 1985). Empirical studies within transaction cost economics have shown that generic assets are best suited for the market, and that investments in specific assets decrease the efficiency of the market (Macher and Richman 2008). When the asset-specificity of a transaction increases to an intermediate level, a hybrid structure is more efficient, and for idiosyncratic assets, a vertically integrated firm is more efficient. Williamson (1985; 1996) has identified different types of asset-specificity, including physical asset-specificity, human asset-specificity, temporal specificity and dedicated assets. These types of asset-specificity have been used extensively 
in empirical studies, and have been operationalized mostly in survey statements applied to a specific case or industry (Bjuggren and Sund 2012; Macher and Richman 2008). We have applied these types of asset-specificity to the Dutch case of balancing transactions. Hence, investments in specific equipment and facilities designed for the bidding process (physical), training employees in sending bids (human), investments that enable 24-hour bidding (temporal), and investments that are specifically tailored to the needs of TenneT (dedicated) represent the different dimensions of asset-specificity (see also table 3 ).

\subsection{Questionnaire}

Table 3 presents the statements on asset-specificity that were included in the questionnaire. Between November 2010 and January 2011, the questionnaire was sent to the ten electricity producers that supply balancing power to TenneT. The questionnaire was only offered to those representatives of the firm responsible for the actual balancing transactions. With respect to the statements, the respondents were requested to answer on a 5-point Likert scale, indicating their agreement or disagreement with the statement. They were also allowed to motivate their answer in writing, and provide details on the type of investments. Out of the ten producers involved in the balancing transaction in the Dutch electricity industry, eight firms participated in the questionnaire. On a scale from 1 to 5 , we will assume the values 1 and 2 as non-specific, 3 and 4 as intermediate and a value of 5 as idiosyncratic. 
Table 3. Questionnaire statements on investments in specific assets

\begin{tabular}{|l|l|}
\hline Physical asset specificity & $\begin{array}{l}\text { To enable the bidding of regulating and reserve power, investments in } \\
\text { equipment and facilities were needed that cannot be used for other activities. }\end{array}$ \\
\hline Human asset specificity & $\begin{array}{l}\text { Investments in specialized human capital were needed to supply bids for } \\
\text { regulating and reserve power. }\end{array}$ \\
\hline Dedicated assets & $\begin{array}{l}\text { We have spent significant resources to ensure that our systems fit with the } \\
\text { system for frequency control of TenneT. }\end{array}$ \\
\hline Physical asset specificity & $\begin{array}{l}\text { The equipment and facilities that are used to bid regulating and reserve } \\
\text { power to TenneT cannot be used for other purposes. }\end{array}$ \\
\hline Dedicated assets & $\begin{array}{l}\text { The procedures and routines we have developed to bid regulating and } \\
\text { reserve power are tailored to the specific situation of TenneT. }\end{array}$ \\
\hline Human asset specificity & $\begin{array}{l}\text { Specialized training and/or hiring employees with the right capabilities are } \\
\text { required to ensure effective bidding. }\end{array}$ \\
\hline Temporal specificity & $\begin{array}{l}\text { Our company has invested in resources that allow bidding for regulating and } \\
\text { reserve power during 24 hours of each day. }\end{array}$ \\
\hline
\end{tabular}

\subsection{Intermediate asset-specificity for balancing}

On the reported scale (from 1 to 5), the median of physical asset-specificity, dedicated assets and temporal specificity were recorded to be intermediate (4), indicating the relevance of these dimensions of asset-specificity in the transactions. On the other hand, the median of human asset-specificity was recorded to be relatively low (2), indicating the minor role of investments in human capital in the balancing transaction. The modes for these dimensions of asset-specificity display a similar pattern and mirror the median indicators. The dispersion of the scores for asset-specificity varies and differs for the separate dimensions. On the human asset-specificity and temporal specificity dimensions, the respondents differed moderately from each other, indicating the relative significance of these dimensions in the transactions for some and the relative insignificance for others (inter-quartile range of 2). The respondents were relatively concerted as far as physical asset-specificity and dedicated assets are concerned (inter-quartile range of 1).

Some examples of specific investments in temporal, dedicated and physical assets by the BRPs are investments in the EDINE-format for sending bidding messages, the system for frequency control for regulating power, the Libra system and 
relatedly the availability of large production facilities for the supply of reserve power. The BRPs that supply regulating and reserve power need to make specific investments to send bids to TenneT. For instance, the messages that include the bids for the supply of regulating and reserve power must be transferred to TenneT in the EDINE-format, which stands for 'Electronic Data Interchange in the Netherlands Energy sector'. The Dutch regulator has made the testing of sending EDINE-messages compulsory for the BRPs. BRPs that wish to exchange bidding messages must be in the possession of certificates for different types of EDINEmessages. These certificates are provided by TenneT. Investments in the EDINEformat are dedicated to the relationship with TenneT. When BRPs send EDINEmessages with bids for the supply of regulating and reserve power to TenneT, they have to comply with a strict time schedule (TenneT 2003: 10), which implies that the balancing transaction is also characterized by temporal specificity. When TenneT calls on the bids for regulating power, it sends so-called delta-signals to the BRPs that supply regulating power. The delta-signals specify how much regulating power the BRPs must supply to (or withdraw from) the network. TenneT sends these signals via a system for frequency control. BRPs need to make substantial investments in technical facilities to be able to receive the deltasignals (ACM 2006). When TenneT calls on the bids for reserve power, it does not send delta-signals, but sends messages to BRPs via a system called Libra (TenneT 2012: 7). BRPs that supply reserve power, on the basis of regulated, long-term contracts, must have large investments in production facilities, since the regulator of the Dutch electricity industry obliged electricity producers with a capacity of more than $60 \mathrm{MW}$ to supply reserve power to TenneT. When the BRPs receive a message via the Libra-system, they must be able to steer production plants that can increase or decrease production within one or two 
PTUs. These responses by BRPs to bid calls of TenneT for regulating and reserve power require that BRPs make large investments in physical assets, and in temporal assets, as the BRPs have to respond within strict and predefined periods of time.

Several examples of investments in specific physical assets and dedicated assets were also provided by the respondents. With respect to the physical assets that are used inside the firm, the respondents indicate to have invested in " $a$ plant planner, an in-house built and dedicated vba for technical plant schemes, an interface with the trade-capture system and regulating power, and a SAT-SCADA system for the execution of regulating power". With respect to physical assets that are needed in the interface with the TSO, the respondents indicate to have invested in the "signal for frequency control to execute regulating power". In response to our statement on dedicated assets, one of the respondents indicated that investments were made by the firm in "ICT and application support", and that the firm hired an external party to ensure their systems fit with those of TenneT.

We conclude that the BRPs have indeed invested in specific assets to supply balancing power to TenneT. These investments mainly concern investments in physical assets, investments dedicated to the relation with TenneT, and investments to allow bidding for regulating and reserve power during 24 hours of each day. The intermediate level of these specific investments (average score of 4 on Likert scale) indicates the efficiency of the hybrid structure for balancing, following the logic of transaction cost economics. The presence of these investments in specific assets also provides an explanation for the absence of a balancing market in the Dutch electricity industry. We have also observed that small firms avoid the Dutch balancing mechanism, which may be explained by the investments that are necessary to participate in the balancing mechanism. 


\section{Policy implications: Creating balancing markets}

As set out in this paper, the need for investments in specific balancing assets by BRPs prevents a balancing market from emerging in the Dutch electricity industry, and limits the amount of participants in the balancing mechanism. In the make-or-buy decision of smaller energy firms with respect to balancing, these firms decide to outsource (buy) their program responsibility to the larger production firms or to the 'aggregators', and they also avoid the high costs associated with supplying balancing power to TenneT. In addition to the specific investments, the Dutch regulator has played an important role in creating a hybrid structure for the balancing transaction. Although the Dutch government has transposed the European electricity directives into their national laws and regulations, including the objective of creating a balancing market, several decisions by the Dutch sector-specific regulator have led to a transformation away from a market for balancing. In the regulator's attempt to prioritize the security of supply, it has imposed long-term contracts and various administrative control mechanisms for the supply of balancing power.

The restricted system of balancing that is currently installed in the Dutch electricity industry hampers the creation of a market and the participation of small players. As one of the respondents argued, the investments for the balancing mechanism require either sufficient production capacity or the possibility for active trading. Previous research has offered the suggestion of lowering the minimum bid size from $5 \mathrm{MW}$ to $1 \mathrm{MW}$, allowing more micro-generation to be offered as regulating and reserve power (Van der Veen and De Vries 2009: 2795), and thereby increasing the participation of smaller players. Aggregator firms 
would only have to bundle a 1000 micro-generation units instead of 5000. In the Dutch electricity industry, 4 aggregator firms are registered as PRPs, but they do not supply balancing power. Perhaps a decrease in bid size could stimulate these firms to offer balancing power, but they would still have to make large specific investments to enable participation in the balancing mechanism.

Our two policy recommendations focus not only on a greater participation of smaller players, but also on decreasing the degree of specific investments in the balancing mechanism. From a transaction cost economics perspective, lowering the temporal specificity, physical asset-specificity, and the dedicated assets of the balancing transaction will increase the comparative efficiency of the market. We suggest that European and national policies should stimulate R\&D into the impact of electricity storage and demand side management techniques on the supply of balancing power, both in terms of cost-efficiencies and reliability of the electricity grid. These two suggestions may not take over the bidding mechanism and the regulated long-term contracts in the short-run, but they may allow for a complementary supply of balancing power to the TSO with a greater participation of smaller players and a lower amount of large specific investments.

\subsection{Electricity storage}

First, energy policies at the European and national level may stimulate technological developments for the efficient storage of electricity. Several studies have demonstrated that electricity storage in batteries of plug-in hybrid electric vehicles (PHEVs) is a source of profitable regulating and reserve power (Kempton and Tomic 2005; Tomic and Kempton 2007; Williams and Kurani 2007). When PHEVs are equipped for vehicle-to-grid power flows, they can offer 
balancing power by either charging or discharging their battery (Andersson et al. 2010: 2752). Walawalker et al. (2007) have demonstrated that other types of electric energy storage facilities, such as flywheel technologies, can be used to supply both regulating and reserve power. Advantages of using batteries in PHEVs or other power storage systems to supply balancing power are the short activation time, flexibility, absence of costs for being available, and lower balancing costs due to battery charging in off-peak hours (Andersson et al. 2010; Bathurst and Strbac 2003; ECN 2004). Vehicle owners may sign a contract with the TSO in which they indicate when their batteries will be available, and they will receive a capacity price and/or an energy price for the regulating or reserve power that is actually delivered. On the basis of the contractual agreements, the TSO may access the balancing power in the batteries of PHEVs (Andersson et al. 2010: 2751-2752). These contracts can be short-term, inflexible, and allow vehicle owners to have a high incentive intensity, as they can increase their stream of revenues by making their battery available. This complementary way of supplying balancing power allows for the participation of small firms and households. It reduces the need for specific investments in large production plants, and for investments that enable immediate responses on the balancing mechanism by energy firms during 24 hours a day. From a transaction cost economics perspective, the use of electricity storage for the supply of balancing power amounts to reducing the physical asset-specificity and the temporal specificity of the balancing transaction. 


\subsection{Demand side management}

Second, demand side management may also reduce the need for large investments and increase the participation of small players. Demand side management refers to different techniques that are aimed at changing both the level and the timing of electricity demand among consumers (Loughron \& Kulich 2004). Strbac and Black (2004) have shown that increases or decreases in power supply via demand side management can serve as a form of regulating or reserve power to balance supply and demand. Strbac (2008: 4424) provides some examples of demand side management techniques, such as direct load control in which a network operator cycles or shuts off consumer appliances. Customers who take part in direct control schemes receive compensation through reduced electricity bills. Strbac (2008: 4424) also points to a technology that is incorporated into electrical consumer appliances and is able to provide frequency regulation. These techniques may increase the number of small actors that are actively contributing to a balance of supply and demand, and that receive an immediate compensation for their efforts. They also reduce the need for large investments in production plants that supply balancing power, and for investments that enable bidding and responses to bids during 24 hours a day.

Our two suggestions do not only apply to the Dutch setting, but will equally affect other European countries. Future research should continue to explore the alignment between governance structures, critical infrastructure transactions, and technological practices (Künneke et al. 2010). We need a better understanding of how various types of asset-specificity can be influenced by the regulator or the system operators, when the policymakers wish to impose a particular governance structure. The effectiveness of energy policies, which currently focus on intended 
governance structures (i.e. the market), may be enhanced with a better understanding of the unintended governance structure outcomes (i.e. the hybrid).

\section{Conclusion}

The European directives for the electricity industry oblige the Member States to implement a market for balancing electricity supply and demand. In this paper, we demonstrated that a market for the supply of balancing power did not emerge in the Dutch electricity industry. We employed a transaction cost economics framework, in which the absence of a market is explained by investments in specific assets. On the basis of a questionnaire that was sent to balancing responsible parties we have shown that these BRPs invest in specific physical, temporal and dedicated assets to supply balancing power. These investments in specific balancing assets do not only explain the absence of a market, but also the lack of participation by small energy firms in the balancing mechanism.

The Dutch balancing transaction is governed instead by a hybrid structure, characterized by an intermediate incentive intensity, monitoring, information disclosure mechanisms, long-term and flexible contracts, and third-party dispute resolution. The Dutch regulator had a determining impact on this structure, as it obliged the energy firms to enter into the long-term contracts, and specified the attributes of the hybrid structure in the Grid and System Codes.

The main contribution of this paper is that it demonstrates that the core argument of transaction cost economics (i.e. the efficiency of the market decreases with increasing specific investments) also applies to the balancing mechanism.

Policymakers at the national and European level that wish to create a balancing market should therefore consider this logic of transaction cost economics, and try to reduce the need for investments in specific assets. 


\section{References}

ACM (2006). Reactie Essent N.V. op NMa Consultatie Concentratie Energiemarkten. https://www.acm.nl/download/documenten/nma/Essent.pdf. Accessed 6 June 2013.

Andersson, S.-L., Elofsson, A.K., Galus, M.D., Goransson, L., Karlsson, S., Johnsson, F., \& Andersson, G. (2010). Plug-in hybrid electric vehicles as regulating power providers: Case studies of Sweden and Germany. Energy Policy, 38, 2751-2762.

Bathurst, G., \& Strbac, G. (2003). Value of combining energy storage and wind in short-term energy and balancing markets. Electric Power Systems Research, 67, 1-8.

Baudisch, A.F. (2007). How demand specificity shapes transaction costs explaining the dynamics of the liberalizing British electricity sector, 1990-2005, Paper presented at the Druid Conference, Copenhagen, June 2007.

http://www2.druid.dk/conferences/viewpaper.php?id=1593\&cf=9. Accessed 18 July 2012.

Beune, R., \& Nobel, F., (2001). System balancing in The Netherlands, Paper presented at Conference on methods to secure peak load capacity on deregulated electricity markets, Stockholm, June 2001.

http://srv128.bluerange.se/Documents/Market\%20Design/conference/2001\%20Pa pers/Beune.pdf. Accessed 18 July 2012.

Bjuggren, P-O., \& Sund, L.-G. (2012). A contractual perspective on succession in family firms: a stakeholder view. European Journal of Law and Economics, doi:10.1007/s10657-012-9331-6.

DTe (2000). Besluit van de directeur van de Dienst uitvoering en toezicht Energie op de bezwaren ingebracht tegen zijn besluit van 21 december 2000, nr. 00-124 tot wijziging van de voorwaarden als bedoeld in artikel 31, eerste lid, onder a en onder c van de Elektriciteitswet 1998, nr. 100264/6. Den Haag: DTe.

DTe \& TenneT (2004). Transparantie van onbalansprijssystematiek. Den Haag /Arnhem: DTe \& TenneT.

ECN (2004). DISPOWER - A socio-economic analysis of technical solutions and practices for the integration of distributed generation. International Conference on the Integration of Renewable Energy Sources and Distributed Energy Resources, 1- 3 December 2004, Brussels.

Eising, R. (2002). Policy learning in embedded negotiations: Explaining EU electricity liberalization', International Organization, 56, 85-120.

European Commission (2003). Directive 2003/54/EC of the European Parliament and of the Council of 26 June 2003 concerning common rules for the internal market in electricity and repealing Directive 96/92/EC. Brussels: EC.

European Commission (2007). DG Competition report on Energy Sector Inquiry. http://ec.europa.eu/competition/sectors/energy/inquiry/full_report_part1.pdf. Accessed 18 July 2012. 
European Commission (2009). Directive 2009/72/EC of the European Parliament and of the Council of 13 July 2009 concerning common rules for the internal market in electricity and repealing Directive 2003/54/EC. Brussels: EC.

Friedrichsen, N. (2012). Governing smart grids: the case for an independent system operator. European Journal of Law and Economics, doi: 10.1007/s10657-012-9345-0.

Glachant, J.-M., \& Saguan, M. (2007). An institutional frame to compare alternative market designs in EU electricity balancing, Working Paper, University of Cambridge.

http://www.eprg.group.cam.ac.uk/wp-content/uploads/2008/11/eprg0711.pdf. Accessed 18 July 2012.

Hortaçsu, A., \& Puller, S. (2008). Understanding strategic bidding in multi-unit auctions: A case study of the Texas electricity spot market. The Rand Journal of Economics, 39, 86-114. International Energy Agency (2000). Energy Policy of IEA Countries - The Netherlands 2000 Review. Paris: IEA.

Joskow, P. (1987). Contract duration and relationship-specific investments: empirical evidence from coal markets. The American Economic Review, 77, 168-185.

Joskow, P. (1996). Introducing competition into regulated network industries: from hierarchies to markets in electricity. Industrial and Corporate Change, 5, 341-382.

Kempton, W., \& Tomic, J. (2005). Vehicle-to-grid power fundamentals: Calculating capacity and net revenue. Journal of Power Sources, 144, 268-279.

Künneke, R., Groenewegen, J., \& Ménard, C. (2010). Aligning modes of organization with technology: Critical transactions in the reform of infrastructures. Journal of Economic Behavior \& Organization, 75, 494-505.

Loughron, D., \& Kulich, J. (2004). Demand-side management and energy efficiency in the United States. Energy Journal, 25, 19-43.

Macher, J., \& Richman, B. (2008). Transaction cost economics: An assessment of empirical research in the social sciences. Business and Politics, 10, 1-65.

Newbery, D. (2004). Electricity liberalisation in Britain: the quest for a satisfactory market design, CMI Working Paper 64, University of Cambridge.

http://www.econ.cam.ac.uk/electricity/publications/wp/ep64.pdf. Accessed 18 July 2012.

Niesten, E., \& Jolink, A. (2012a). Incentives, opportunism and behavioral uncertainty in electricity industries. Journal of Business Research, 65, 1031-1039.

Niesten, E., \& Jolink, A. (2012b). Regulating opportunism in the electricity industry and consumer interests. Utilities Policy, 20, 38-45.

Paulus, M., \& Borggrefe, F. (2011). The potential of demand-side management in energyintensive industries for electricity markets in Germany. Applied Energy, 432-441.

Sioshansi, R., \& Oren, S. (2007). How good are supply function equilibrium models: An empirical analysis of the ERCOT balancing market. Journal of Regulatory Economics, 31, 1-35.

Strbac, G., \& Black, M. (2004). Future Value of Storage in the UK. Department of Trade and Industry, London. 
Strbac, G. (2008). Demand-side management: Benefits and challenges. Energy Policy, 36, 44194426.

TenneT (2003). Handleiding bieden regel- en reservevermogen.

http://www.tennet.org/images/Handleiding\%20bieden\%20Regel-

\%20en\%20ReserveVermogen\%202.1_tcm41-19020.pdf. Accessed 18 July 2012.

TenneT (2005). De onbalansprijssystematiek per 01-01-2001, herzien per 26-10-2005.

http://www.tennet.org/images/onbalansprijssystematiek\%20aangepaste\%20prikke

lcomponent_tcm41-11583.pdf. Accessed 18 July 2012.

TenneT (2007). Uitvoeringsregels met betrekking tot Net- en Systeemcode.

http://www.tennet.org/images/MO-

262\%20Uitvoeringsregels\%20totaal_3.0_tcm41-13198.pdf. Accessed 18 July 2012.

TenneT (2011). Notitie Productinformatie Regelvermogen - 19 mei 2011.

http://Www.tennet.org/images/SOC_11-139_Productinformatie_regelvermogen.pdf.

Accessed 6 June 2013.

TenneT (2012). Uitvoeringsregels met betrekking tot Net- en Systeemcode - versie januari 2012.

http://www.tennet.eu/nl/nl/over-tennet/nieuws-pers-publicaties/publicaties/technische-

publicaties/uitvoeringsregels.html. Accessed 6 June 2013.

Tomic, J., \& Kempton, W. (2007). Using fleets of electric-drive vehicles for grid support. Journal of Power Sources, 168, 459-468.

Van der Veen, R., \& De Vries, L. (2009). The impact of microgeneration upon the Dutch balancing market. Energy Policy, 37, 2788-2797.

Vandezande, L., Meeus, L., Belmans, R., Saguan, M., \& Glachant, J.-M., (2010).

Well-functioning balancing markets: A prerequisite for wind power integration. Energy Policy, 38, 3146-3154.

Walawalkar, R., Apt, J., \& Mancini, R. (2007). Economics of electric energy storage for energy arbitrage and regulation in New York. Energy Policy, 2558-2568.

Williams, B., \& Kurani, K. (2007). Commercializing light-duty plug-in/plug-out hydrogen fuel cell vehicles: Mobile electricity technologies and opportunities. Journal of Power Sources, 166, 549-566.

Williamson, O. (1985). The economic institutions of capitalism: Firms, markets, relational contracting. New York: Free Press.

Williamson, O. (1991). Comparative economic organization: the analysis of discrete structural alternatives. Administrative Science Quarterly, 36, 269-296.

Williamson, O. (1994). Visible and invisible governance. The American Economic Review, 84, 323-326.

Williamson, O. (1996). The mechanisms of governance. Oxford: Oxford University Press.

Williamson, O. (2000). The new institutional economics: taking stock, looking ahead. Journal of Economic Literature, 38, 595-613. 